EPiC Series in Engineering
Volume 3, 2018, Pages 2033-2041
HIC 2018. 13th International
Conference on Hydroinformatics

\title{
Advanced Integrated Real-Time Control of Combined Urban Drainage Systems using MPC: Badalona Case Study
}

\author{
Congcong Sun ${ }^{1 *}$, Bernat Josep-Duran ${ }^{2}$, Gabriela Cembrano ${ }^{1,2}$, Vicenç Puig ${ }^{1}$ \\ and Jordi Meseguer ${ }^{2}$ \\ ${ }^{1}$ Institut de Robòtica I Informàtica Industrial (CSIC-UPC), Barcelona 08028, Spain \\ ${ }^{2}$ CETaqua, Water Technology Centre, Barcelona 08028, Spain \\ csuneiri.upc.edu
}

\begin{abstract}
Combined urban drainage system (CUDS) collect both wastewater and raining water through sewer networks to wastewater treatment plants (WWTP) before releasing to the environment. During storm weather, rain and wastewater can overload the capacity of the CUDS and/or the WWTPs, producing combined sewer overflows (CSO). In order to improve the management efficiency of CUDS, advanced real-time control (RTC) of detention and diversion infrastructures in the sewer systems has been proven to contribute to reducing the CSO volumes. This work considers the integrated RTC of sewer network and WWTPs based on model predictive control (MPC) and taking into account the water quality as well as quantity, with the objective of minimizing the environmental impact of $\mathrm{CSO}$ on receiving waters. The control approach is validated using a real pilot Badalona sewer network in Spain. The first results, discussion and conclusions are also provided.
\end{abstract}

\section{Introduction}

Integrated urban drainage systems are mainly composed by urban drainage networks (UDN), wastewater treatment plants (WWTP) and the receiving water body. They collect and convey urban wastewater and rain water run-off through sewer network to WWTP for treatment before releasing it to the environment. During heavy rain events, mixed sewage can overload the system and produce combined sewer overflows (CSO), which are harmful to the water environment (Joseph-Duran, Ocampo-Martínez, \& Cembrano, 2014) (Gasperi, Garnaud, Rocher, \& Moilleron, 2008) (Becouze, Bertrand-Krajewski, Dembélé, Cren-Olivé, \& Coquery, 2009). Up to now, the UDN and WWTPs are usually operated separately by different utilities and their control is generally based on water quantity

${ }^{*}$ Masterminded EasyChair and created the first stable version of this document 
variables. In order to improve the management efficiency of combined urban drainage systems (CUDS) and to minimize the pollutants impact on the receiving environment, the integrated control scheme of CUDS using real-time quantity and quality data is proposed as a solution, which is also the main goal of LIFE EFFIDRAIN project (www.life-effidrain.eu).

Real-time control (RTC) has been proven (Butler \& Schütze, 2005) (Fu, Khu, \& Butler, Multiobjective optimization of urban wastewater systems using ParEGO: A comparison with NSGA II, 2008) (Fu, Khu, \& Butler, Optimal distribution and control of storage tank to mitigate the impact of new developments on receiving water quality., 2010) as a reliable solution to achieve better performance in effective operation of CUDS (Schütze, Butler, \& Beck, 2002). Among the current RTC techniques, Model Predictive Control (MPC), which based on solving an optimal control problem not only with current measurements but also predictive behaviours in a certain horizon, has been successfully implemented as an efficient method to produce optimal strategies for CUDS (Puig, et al., 2009) (Xu, van Overloop, \& Van de Giesen, 2013). Considering the complexity of the quantity and quality spatial/temporal evolution in CUDS, appropriate conceptual quality models are required to apply RTC efficiently in CUDS taking into account effluent quality.

The main contribution of this paper is the application of integrated MPC based RTC control scheme of CUDS with simplified quality models to minimize pollutant discharges to the receiving environment. Total suspended solid (TSS) has been selected as a representative variable of the water quality, because it may be correlated with turbidity, which is measured continuously and also, because it is useful to estimate other quality variables. The Badalona sewer network, which is a real sewer and WWTP pilot in Badalona, Spain, has been used as case study.

This paper is organized as follows: Section 2 presents the simplified quality models used for control. Section 3 presents the application and results. Finally, main conclusions are discussed in Section 4.

\section{Simplified Quality Models}

In order to develop an integrated RTC scheme for CUDS considering quality model, simplified quality modelling approaches, which can represent the main dynamics of the quality elements with less complexity, are required (Puig, et al., 2009) (Cluckie, Lane, \& Yuan, 1999) (Norreys \& Cluckie, 1997). Physically, model of TSS, which is a representative quality parameter in CUDS, is affected by solid accumulation in the urban catchments, sediment washoff by rainfall, solids transport, erosion and deposition in sewer networks and detention tanks (Betrand-Krajewski, 2006).

The proposed simplified conceptual modelling approaches are mainly designed to predict the evolution of TSS over the predictive control horizon of the MPC-based RTC scheme. The TSS transport modelling approach in a sewer is originated from a virtual tank model (Cembrano, et al., 2004) (Sun, et al., 2017, July), while the TSS model for junction nodes are designed using mass balance equation (Sun, et al., 2017, July). Model details about the simplified quality models for TSS in the sewers, junction nodes can be referred in (Sun, et al., 2017, July), where the proposed modelling approach has been coordinated and validated using a virtual reality. The least square fitting index is used to measure the goodness of approximation of the simplified models, which confirm their effectiveness (Sun, et al., 2017, July).

The simplified dynamic model of TSS in a detention tank is based on a simple representation of the mass deposition and erosion processes, together with water volume balance. As shown in Figure 1, a detention tank has the capacity to collect water volume $(V)$ and TSS mass $(M)$ based on the difference between upstream (Qup: $\mathrm{m}^{3} / \mathrm{s} ;$ TSSup: $: \mathrm{m}^{3}$ ) and downstream (Qdown: ${ }^{3} / \mathrm{s} ; \mathrm{TSS} d o w n: \mathrm{g} / \mathrm{m}^{3}$ ). 
As referred in (Cembrano, et al., 2004) (Puig, et al., 2009), the hydraulic dynamics of a catchment and a detention tank (see Figure 1) can be written in discrete-time as:

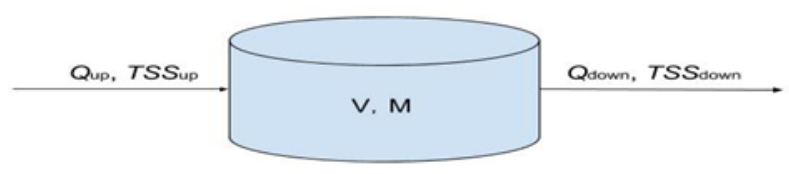

Figure 1: Detention Tank

$$
V(k+1)=V(k)+\Delta t\left(Q_{\text {up }}(k)-Q_{\text {down }}(k)\right)
$$

where $V$ is water volume, $k$ is the discrete-time instant, $\Delta t$ means control time interval and $Q$ is the flow of this tank.

Thus, the hydraulics models of CUDS are represented using water volumes (inside detention tanks, catchments and in-line detention sewers), flows through sewers, pumps and gates, as well as input flows from contributing catchments, flows to the WWTP and CSO flows.

Considering the TSS models in sewers (TSSup and TSSdown) presented by (Sun, et al., 2017, July), the dynamics of TSS mass in a detention tank (see Figure 1) $M$ can be computed as:

$$
M(k+1)=(1-\alpha) M(k)+\Delta t\left(Q_{u p}(k) T S S_{u p}(k)-Q_{\text {down }}(k) T S S_{\text {down }}(k)\right)
$$

where $\alpha$ is a parameter taking values between -1 and 1 , being calibrated by means of the training data and represents the sedimentation and erosion effects in a detention tank. In order to show the first results of the integrated RTC scheme, in this paper, $\alpha$ is set as a constant value 0.3 , which means the detention tank produces a sedimentation of $30 \%$ of the suspended solids in a time step.

Afterwards, according to the physical definition of TSS, the concentration of total suspended solids in the detention tank, and also in the outlets is presented as (valid for $\mathrm{V}>0$ );

$$
T S S_{\text {down }}(k+1)=\frac{M(k+1)}{V(k+1)}
$$

The evolution of flows and TSS can be obtained by solving the following Optimal Control Problem at every time instant, where the CUDS quantity and quality simplified models are used as constraints.

$$
x(k+1)=f(x(k), u(k), w(k)), \quad k=t, \ldots, t+H-1
$$

where $\boldsymbol{x}(t)$, are system states representing water volume in tanks and TSS mass; $\boldsymbol{u}(t)$ are control actions of flow across commanded gates and $\boldsymbol{w}(t)$ are disturbances related to rain intensity and runoff.

\section{Model Predictive Control}

The objective of using MPC as the basic method for the integrated RTC of CUDS is to compute, in a predictive way, the manipulated inputs to achieve optimal performance of whole system according to a given set of control objectives and predefined performance indices. As in (Puig, et al., 2009) (Cembrano, Wells, Quevedo, Perez, \& Argelaguet, 2000) (Overloop, 2006) (Marinaki \& Papageorgiou, 2005), such controllers are suitable to be used in the global and supervisory control of networks related to CUDS.

The main goals concerned with hydraulics of CUDS are summarized in the following optimization objectives:

(1) Minimizing the CSO discharges from the sewer network to the receiving environment. This objective is expressed as; 


$$
J_{c s o}(k)=\sum_{i=1}^{I} \max \left(0, u_{c s o}^{i}(k)-u_{\text {max }}^{i}\right)^{T} \max \left(0, u_{c s o}^{i}(k)-u_{\text {max }}^{i}\right)
$$

where $\boldsymbol{I}$ is the number of CSOs, $u_{\text {max }}^{i}$ (which equals 0 in practical) is the maximal flow allowed by $u_{c s o}^{i}$ just before releasing sewage to the receiving environment. This term can be seen as a special case of the first objective where only the overflows going to the receiving environment are taken into account.

(2) Maximizing usage of the WWTP by minimizing the difference between flow sent to WWTP $u_{w w}$ and the maximum flow allowed to be accepted by the WWTP. This objective is expressed as:

$$
J_{w w t p}(k)=\min \left(0, u_{w w}(k)-u_{w w t p}\right)
$$

where $u_{w w t p}$ is the maximal allowed flow to the WWTP.

(3) Minimizing the excess of flows/volumes compared to their operationally safe values for tanks, virtual tanks and sewers. This is expressed as the sum (or squared sum) of positive deviations:

$$
J_{\text {safe }}(k)=\sum_{q=1}^{Q}\left(\bar{x}^{q}{ }_{v o l}-x^{q}{ }_{v o l}(k)\right)^{T}\left(\bar{x}^{q}{ }_{v o l}-x^{q}{ }_{v o l}(k)\right)
$$

where $Q$ is the sum number of tanks and virtual tanks, $x^{q}{ }_{v o l}$ represents the tank volume, $\bar{x}^{q}{ }_{v o l}$ is the safety level of the tank.

(4) Minimizing variations of the control actions from one-time step to the next for the detention gate, diversion gate or pumps. This objective aims to providing a smooth strategy for the control elements and can be expressed as:

$$
J_{\text {smoothness }}(k)=\sum_{n=1}^{N}\left(u^{n}(k)-u^{n}(k-1)\right)^{T}\left(u^{n}(k)-u^{n}(k-1)\right)
$$

The main goal concerned with quality of CUDS is minimizing the pollutant loads to the environment. So additional goal is added that aims at minimizing the overflowed mass of suspended solids to the environment. The quality objective function to be minimised is defined as follows:

$$
J_{\text {quality }}=J_{\text {Mass }}
$$

where Mass is the sum of TSS mass in all the contributions of different effluents over the prediction horizon, where, at each effluent, the TSS mass at one-time interval may be computed as:

$J_{\text {Mass }}(t)=\Delta t \cdot \sum_{i=1}^{C} T_{S S}(t) \cdot\left(u_{c s o}^{i}(k)-u_{\text {max }}^{i}\right)$

Finally, the combination of these objectives is a weighted sum of the above-described objectives.

$J(x, u, w)=a_{c s o} J_{c s o}+a_{w w t p} J_{w w t p}+a_{\text {safe }} J_{\text {safe }}+a_{\text {smoothness }} J_{\text {smoothness }}+a_{\text {Mass }} J_{\text {Mass }}$

The weights $a_{c s o}, a_{w w t p}, a_{\text {safe }}, a_{\text {smoothness }}, a_{\text {Mass }}$ are defined taking into account their prioritization of the partial objectives and the numerical range of variation of each of them. The prioritization of these control objectives is performed by using a set of appropriate weights (Puig, et al., 2009).

Finally, taking into account the objective function (11) and the system dynamics of CUDS (4), the optimization problem associated to the MPC controller can be written as follows:

S.t.

$$
\min _{\boldsymbol{x}, \boldsymbol{u}} J(\boldsymbol{x}, \boldsymbol{u}, \boldsymbol{w})
$$

$$
\begin{gathered}
x(k+1)=f(x(k), u(k), w(k)), \quad k=t, \ldots, t+H, \\
h(x(k), u(k), w(k)) \leq 0, \quad k=t, \ldots, t+H, \\
x_{\min } \leq x(k) \leq x_{\max }, \quad k=t, \ldots, t+H, \\
u_{\min } \leq u(k) \leq u_{\max }, \quad k=t, \ldots, t+H .
\end{gathered}
$$

where $\boldsymbol{x}(t)=(x(t), x(t+1), \ldots, x(t+H))$ is the sequence of system states representing water volume in tanks and the TSS mass; $\boldsymbol{u}(t)=(u(t), u(t+1), \ldots, u(t+H))$ is the sequence of control 
actions of flow across a commanded gate; $\boldsymbol{w}(t)=(w(t), w(t+1), \ldots, w(t+H))$ is the sequence of disturbances related to rain intensity and runoff. $\boldsymbol{u}_{\min }, u_{\max }, x_{\min }, x_{\max }$, are their physical limits.

\section{Application and Results}

The MPC-based integrated RTC strategy is implemented using the GAMS optimization library (Richard, 2016) with the proposed conceptual models for CUDS. The Badalona urban drainage network with the related Besos WWTP is used as a functional demonstration.

\subsection{Badalona Sewer Network}

Badalona is located in the east of Catalonia (Spain) and is part of Barcelona metropolitan area, with more than 215.654 inhabitants in a land area of $21.2 \mathrm{~km}^{2}$, which occasionally suffers heavy rains with large intensities and possible flash floods event. A simplified model of the Badalona urban drainage system can be derived which contains one detention tank with contributions from two different catchments, as shown in Figure 2. Catchments VT1 and VT3 send water through gates G1 and G2 to the detention tank T1. Afterwards, the pump P draw water through T1 to the WWTP before releasing to the sea. When the capacity of the WWTP, the interceptors or the pumping towards these is exceeded, CSO occurs at different points on the coast.

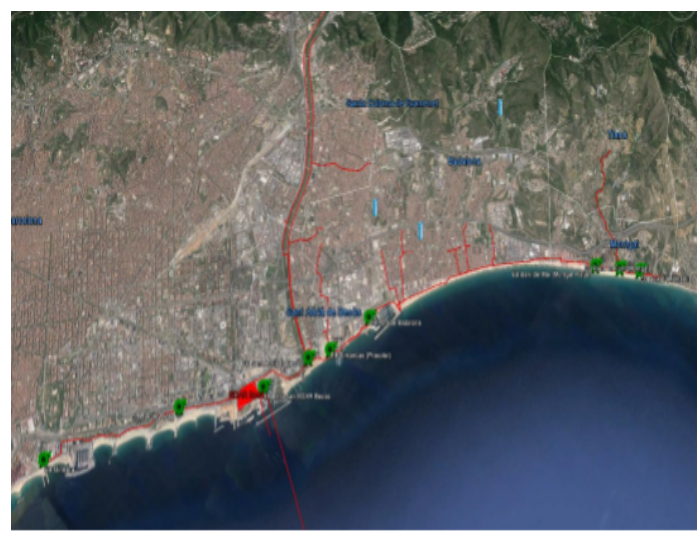

a. Badalona Pilot

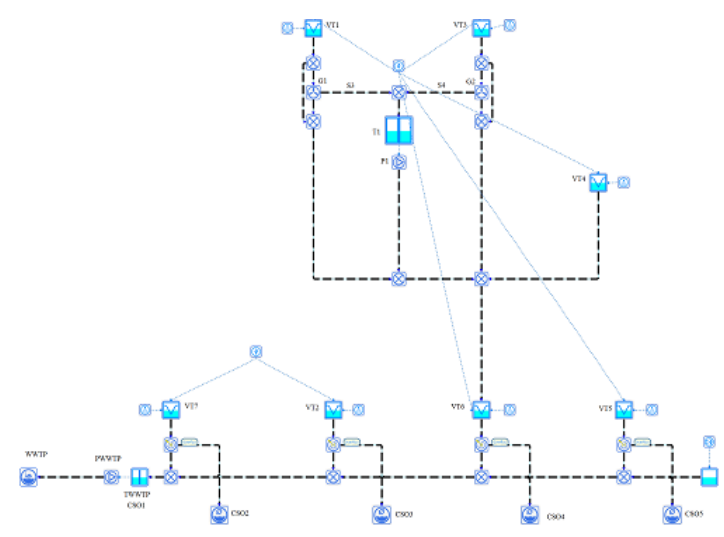

b. Conceptual Badalona Sewer Network

Figure 2: Badalona Sewer Network

\subsection{Rain and TSS Scenarios}

Two artificial sets of TSS data (Table 1) have been created to show how the quality-and-quantity control deals with waters with different qualities (a different TSS) producing different control strategies of tank filling and emptying. In scenario 1, VT1 and VT3 have the same TSS. In Scenario 2, the numbers 15 and 1 means the TSS input from catchment VT3 is 15 times of TSS input from catchment VT1 in Scenario 1. Firstly, MPC with only hydraulic optimization will be applied as a baseline case. Then, MPC with both hydraulic and quality optimizations for each scenario will show, two different kinds of strategies. Results will be compared to give conclusions.

\section{Table 1 Scenario Definitions for TSS}




\begin{tabular}{|lll|}
\hline & VT1 & VT3 \\
Scenario 1 & 15 & 15 \\
Scenario 2 & 1 & 15 \\
\hline
\end{tabular}

\subsection{Results and Discussion}

The MPC strategy of the Badalona urban drainage system has been chosen to demonstrate the MPC with hydraulics and quality equations. In this test scenario, and MPC model with the hydraulic equations and the simplified TSS model for the junctions and tanks have been implemented, in order to compare the control strategies obtained when considering CSO quantity-and-quality objectives, to those obtained using only quantity objectives.

MPC strategy is implemented using GAMS (Puig, et al., 2009) (Richard, 2016) to minimize CSO and pollutant load discharges. This strategy allows flows with bigger TSS to have higher in order to be detained and be sent gradually to the WWTP after raining.

In Scenario 1, the catchment VT1 and VT3 have the same TSS. Comparing with hydraulic-based MPC optimization, limited TSS mass release reduction can be achieved when using MPC with both hydraulic and quality optimizations as shown in Figure 3.

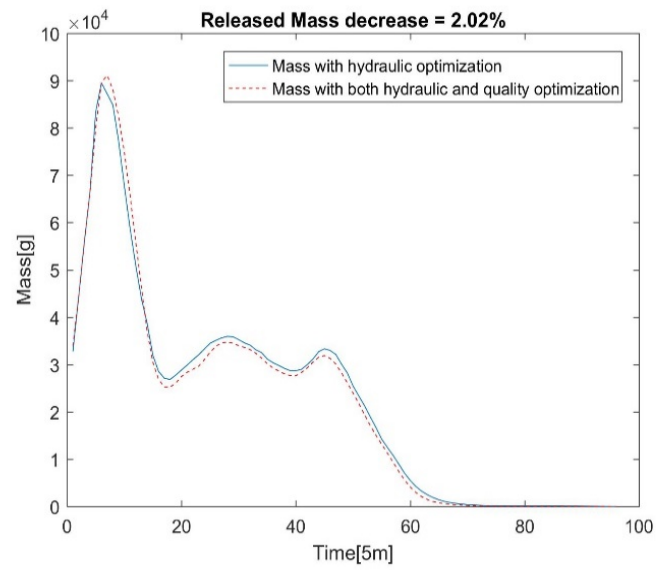

a. MASS

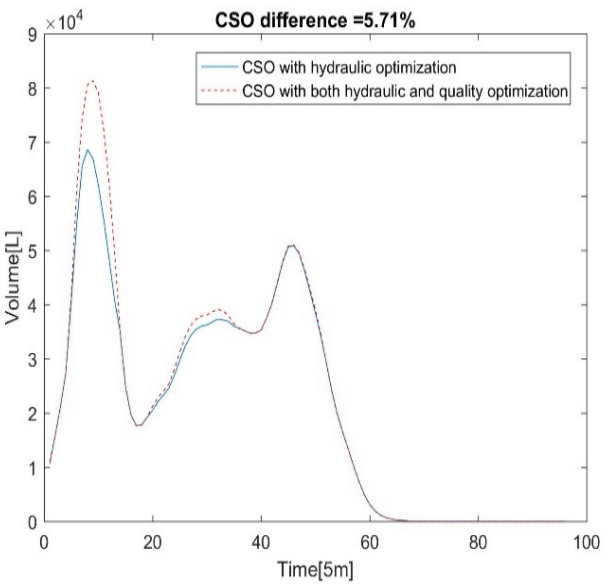

b. $\mathrm{CSO}$

Figure 3: Results Comparisons for Scenarios 1

In Scenario 2, the catchment VT1 and VT3 have different TSS inputs, where TSS input from VT3 is 15 times of TSS input from VT1. According to the quality strategy, flow from VT3 has higher priority 
to be sent to tank T1 for detention than VT1, which has better quality and will be released firstly if CSO is unavoidable. After that, more TSS mass and CSO can be decreased as shown in Figure 4.

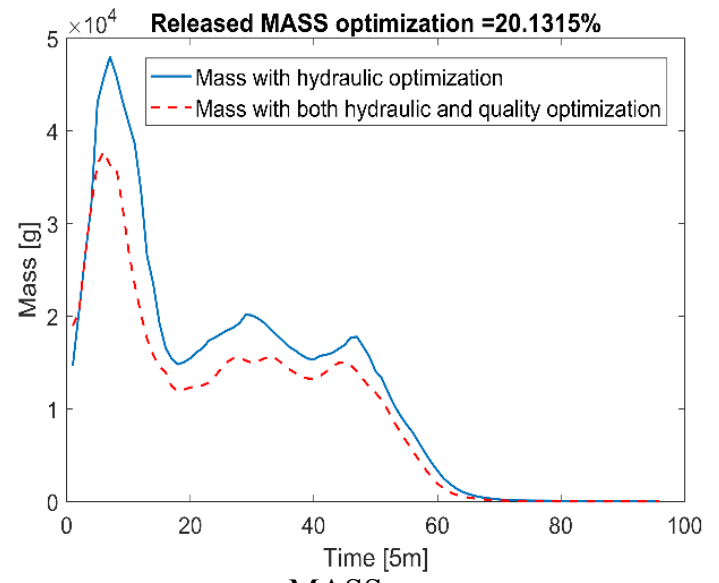

a. MASS

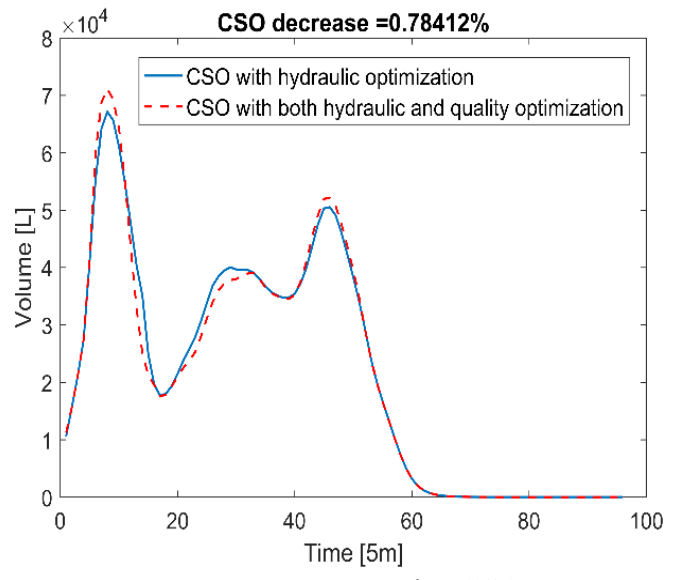

b. $\mathrm{CSO}$

Figure 4: Results Comparisons for Scenarios 2

In this comparison, it has been assumed that catchment VT1 has a significantly higher TSS contribution than catchment VT3. Firstly, the MPC controller with hydraulics-only optimization was implemented for reference. Then, MPC controller with both hydraulics and quality optimization was implemented. The results of both strategies are compared in terms of how the tank is filled and also on the final impact of CSO.

Obviously, when the equations do not consider quality, the control strategy will allow the filling of the tank from catchment VT1 and VT3 indifferently. However, when considering the water quality, the optimizer should produce a strategy that favours the detention of the most polluted water.

Figure 5 shows the aggregated results of the Scenario 2, comparing the flow strategies for water inlet to the tank coming from VT1 and VT3. When applying the quality optimization, flow from VT3 (QS4) has higher priority to be sent to tank T1 for detention than flow from VT1 (QS3), which has better quality and will be released firstly if CSO is unavoidable. As presented in Figure 5, QS3 has been doubled by MPC with hydraulic and quality optimization, while QS4 has been decreased more than $60 \%$, with respect to the flow strategies obtained using only hydraulics.

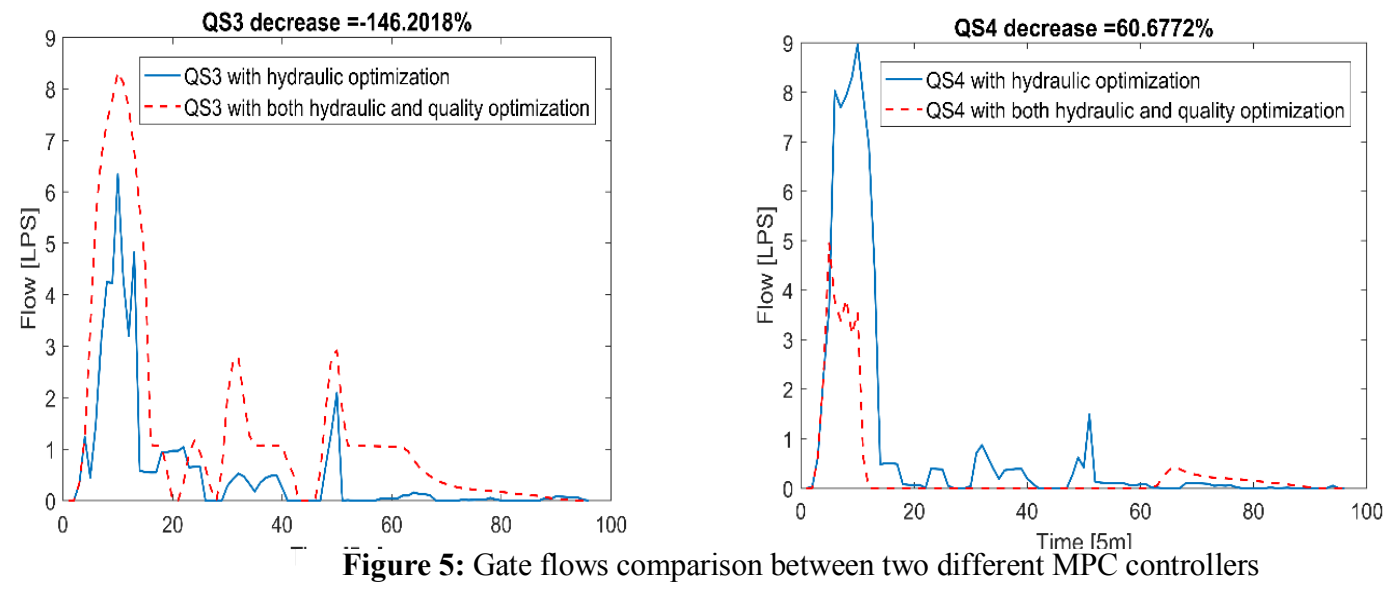


Table 2 presents more details for the results produced by two different MPC strategies in both scenarios. It can be observed that MPC with both hydraulic and quality optimizations works better to decrease CSO impact of TSS mass, the improvement is remarkable for the scenarios when TSS are different. All the values are provided in economic unit (e.u.) due to confidentiality issues.

Table 2 Performance Comparisons of integrated MPC scheme

\begin{tabular}{|l|c|c|c|c|}
\hline \multicolumn{2}{|c|}{} & $\begin{array}{c}\text { MPC with Hydraulic } \\
\text { Optimization }\end{array}$ & $\begin{array}{c}\text { MPC with both Quantity } \\
\text { and Quality Optimization }\end{array}$ & $\mathrm{n}$ \\
\hline \multirow{2}{*}{ Scenario 1 } & Mass & 432 & 424 & $2.02 \%$ \\
\cline { 2 - 5 } & CSO & 201 & 213 & $-5.71 \%$ \\
\hline \multirow{2}{*}{ Scenario 2 } & Mass & 1008 & 805 & $20.13 \%$ \\
\cline { 2 - 5 } & CSO & 118 & 117 & $0.784 \%$ \\
\hline
\end{tabular}

Two artificial sets of TSS data (Table 1) have been created to show how the quality-and-quantity control deals with waters with different qualities (a different TSS) producing different control strategies of tank filling and emptying. In scenario 1, VT1 and VT3 have the same TSS. In Scenario 2, the numbers 15 and 1 means the TSS input from catchment VT3 is 15 times of TSS input from catchment VT1 in Scenario 1. Firstly, MPC with only hydraulic optimization will be applied as a baseline case. Then, MPC with both hydraulic and quality optimizations for each scenario will show, two different kinds of strategies. Results will be compared to give conclusions.

\section{Conclusions}

This paper presents the results of MPC for CUDS including quality model. This work is part of the project LIFE EFFIDRAIN (Efficient Integrated Real-time Control in Urban Drainage and Wastewater Treatment Plants for Environmental Protection). From the experiments and comparisons presented in the paper, the following conclusions can be extracted:

(1) The integrated MPC based RTC scheme with only hydraulic optimization is able to optimize CSO of CUDS during storm weather;

(2) The MPC control strategy which considers quality optimization can work better than the MPC strategy that only considers hydraulic optimizations because it allows decreasing the suspended solid mass in discharges, especially in the scenarios where TSS inputs have important differences.

\section{Acknowledgment}

The authors wish to thank the support received by the European Commission research grant of project LIFE EFFIDRAIN (LIFE14 ENV/ES/000860), also thank the support from Spanish national project DEOCS (DPI2016-76493-C3-3-R). The authors also want to thank Bordeaux Metropole and Aigües de Barcelona for the financial and technical support. This work is also supported by the Spanish State Research Agency through the María de Maeztu Seal of Excellence to IRI (MDM-2016-0656). 


\section{References}

Becouze, C., Bertrand-Krajewski, J. -L., Dembélé, A., Cren-Olivé, \& Coquery, M. (2009). Preliminary assessment of fluxes of priority pollutants in stormwater discharges in two urban catchments in Lyon. 13th of IWA intern. confer. on Diffuse Pollu. and Integ. Waters. Manage. Seoul: South Korea.

Betrand-Krajewski, J. (2006). Modelling of sewer solids production and transport. J. Modell. of Sedi. Trans. and Proce., INSA de Lyon.

Butler, D., \& Schütze, M. (2005). Integrating simulation models with a view to optimal control of urban wastewater systems. J. Environ. Modell. and Softw., 20(4), 415-426.

Cembrano, G., Quevedo, J., Salamero, M., Puig, V., Figueras, J., \& Martí, J. (2004). Optimal control of urban drainage systems. A case study. J. Contr. Engin. Pract., 12(1), 1-9.

Cembrano, G., Wells, G., Quevedo, J., Perez, R., \& Argelaguet, R. (2000). Optimal control of a water distribution network in a supervisory control system. Control Eng. Pract., 8(10), 1177-1188.

Cluckie, I., Lane, A., \& Yuan, J. (1999). Modelling large urban drainage systems in real time. J. Wat. Sci. Technol., 39(4), 21-28.

Fu, G., Khu, S., \& Butler, D. (2008). Multi-objective optimization of urban wastewater systems using ParEGO: A comparison with NSGA II. 11th Inte. Confe. on Urb. Drain., (pp. 1-8).

Fu, G., Khu, S., \& Butler, D. (2010). Optimal distribution and control of storage tank to mitigate the impact of new developments on receiving water quality. J. Environ. Engine., 335-342.

Gasperi, J., Garnaud, S., Rocher, V., \& Moilleron, R. (2008). Priority pollutants in wastewater and combined sewer overflow. J. Scien. of the Tot. Environ, 263-272.

Joseph-Duran, B., Ocampo-Martínez, C., \& Cembrano, G. (2014). Hybrid modelling and receding horizon control of sewer network. Water Resources Research, 263-272.

Marinaki, M., \& Papageorgiou, M. (2005). Optimal Real-time Control of Sewer Networks. Secaucus, NJ: Springer-Verlag.

Norreys, R., \& Cluckie, I. (1997). A novel approach to real-time modelling of large urban drainage systems. J. Wat. Sci. Technol., 36(8-9), 19-24.

Overloop, P. (2006). Model predictive Control on Open Water Systems. Delft, The Netherland: Delft Univ. Press.

Puig, V., Cembrano, G., Romera, J., Quevedo, J., Aznar, B. R., \& Cabot, J. (2009). Predictive optimal control of sewer networks using CORAL tool: application to Riera Blanca Catchment in Barcelona. Water science \& Technology, 60(4), 869-878.

Richard, E. (2016). GAMS - A Users' Guide. Washington, DC, USA: GAMS Develop. Corpor.

Schütze, M., Butler, D., \& Beck, M. (2002). Modelling, Simulation and Control of Urban Wastewater Systems. London: Springer.

Sun, C., Joseph-Duran, B., Maruejouls, T., Cembrano, G., Meseguer, J., Puig, V., \& Litrico, X. (2017, July). Real-time control-oriented quality modelling in combined urban drainage networks. IFAC 2017 World Congress, (pp. 4002-4007). Toulouse, France.

Xu, M., van Overloop, P., \& Van de Giesen, N. (2013). Model reduction in model predictive control of combined water quantity and quality in open channels. J. Environ. Modell. and Softw., 42, 7287. 